\title{
The role of lymphadenectomy during lung metastasectomy
}

\author{
Jon Zabaleta, Borja Aguinagalde, Iker López, Arantza Fernandez-Monge, José Miguel Izquierdo
}

Thoracic Surgery Department, Basque Health Service, Donostialdea Integrated Health Organisation, San Sebastian, Spain

Contributions: (I) Conception and design: J Zabaleta, B Aguinagalde; (II) Administrative support: All authors; (III) Provision of study material or patients: I López; (IV) Collection and assembly of data: A Fernandez-Monge, JM Izquierdo; (V) Data analysis and interpretation: B Aguinagalde, J Zabaleta; (VI) Manuscript writing: All authors; (VII) Final approval of manuscript: All authors.

Correspondence to: Jon Zabaleta. Donostia University Hospital, Paseo Dr Beguiristain s/n, 20014 Donostia, Spain. Email: jon.zabaletajimenez@osakidetza.eus.

\begin{abstract}
Lymph node involvement implies the presence of two routes of dissemination in patients with lung metastasis. For this reason, we assessed its impact on patients undergoing surgery for lung metastasis. In this review, we have sought to summarise the results of studies analysing the presence of thoracic lymph node involvement in patients who have undergone surgery for lung metastasis from different points of view: its impact on survival, the risk factors for developing lymph node metastasis, the attitude of surgeons towards lymphadenectomy in this population, the safety of systematic lymphadenectomy and the impact of systematic lymphadenectomy on survival.
\end{abstract}

Keywords: Lung metastases; lung metastasectomy; pulmonary metastasectomy; lymphadenectomy; survival; prognostic factors

Received: 06 May 2019; Accepted: 27 May 2019; published: 28 June 2019.

doi: 10.21037 /jovs.2019.05.08

View this article at: http://dx.doi.org/10.21037/jovs.2019.05.08

\section{Introduction}

Systematic mediastinal lymphadenectomy or sampling is routinely performed for primary neoplasm of the lung, including adenocarcinoma, squamous cell carcinoma and neuroendocrine tumours (1). Despite a paucity of randomized clinical trial data, it is now generally accepted that overall survival for many tumour types is improved with resection of limited metastases in carefully selected patients (2). Nonetheless, controversy exists surrounding the need for assessment of mediastinal lymph nodes during pulmonary metastasectomy (1). Given the current understanding of tumour biology, it is assumed that metastases to thoracic lymph nodes would convey a worse prognosis. The lungs are an ideal metastatic goal for haematogenously disseminated tumours due to their nature: cells from the lung parenchyma are very close to the vascular space (it being an end organ with small capillaries) and it is a nutrient-rich environment where there is a very good supply of both blood and oxygen (3). Additionally, the lungs produce certain cytokines (e.g., CXCL12) that are responsible for initiating the signalling for leukocytes, neutrophils and other effector cells that induces their movement from the blood towards sites of infection or tissue damage (3). For this reason, lymph node involvement implies the presence of two routes of dissemination, haematogenous and lymphatic, and hence, overall and disease-free survival rates are expected to be poorer in patients with mediastinal lymph node involvement (3-5).

\section{Strengths and weaknesses of the international registry of lung metastasis}

Over recent years, since Pastorino published the results of the International Registry of Lung Metastasis in 1997 (2), resection of lung metastasis from primary non-pulmonary cancer has become an essential part of the activity of thoracic surgery departments (6). While we are still waiting for the results of the first clinical trial on lung metastasis (PulMIC trial) (7), several case series $(8,9)$ and metaanalyses $(10,11)$ have focused on the factors that affect survival following metastasectomy seeking to bring the list of factors proposed by Pastorino up to date. At present, the three factors suggested in 1997 seem to remain valid: status 
of surgical margins, disease-free interval and number of lung metastases.

The registry has some limitations, however, for analysing the effect of lymph node involvement on survival (12): data were gathered on patients from 18 countries, preoperative radiological techniques differed between hospitals, as did the indications for preoperative mediastinoscopy, and lymphadenectomy was only performed in $4.6 \%$ of cases (2).

Given all of this, we wanted to analyse studies published in recent years to further explore the role of lymphadenectomy in patients who undergo surgery for lung metastasis.

\section{Impact of thoracic lymph node involvement on survival following lung metastasectomy}

As we have indicated above, lymph node involvement implies the presence of two routes of tumour dissemination, and given this, it is not surprising that patients with lymph node involvement have lower survival rates. Numerous retrospective studies based on patients who have undergone surgery for lung metastasis from colorectal cancer published in recent years refer to the impact of lymph node involvement on survival (8-11). On the one hand, some studies such as that of Nanji et al. (13) observed a negative effect on survival. After studying 420 patients, they concluded that lymph node involvement was the best prognostic factor [hazard ratio (HR) 2.08; 95\% CI, 1.41-3.07]. Renaud et al. (14) reported similar results in their study of 320 patients who underwent systematic lymphadenectomy. Specifically, they observed that patients with no lymph node involvement survived twice as long as those with lymph node involvement (median survival 94 months versus 42 months in patients with positive lymph node involvement). On the other hand, we have also found studies that did not find significant differences, such as those of Sponholz et al. (15) and Kumar et al. (16). Sponholz studied 54 over-70-year-old who underwent surgery in Germany, and the only factors that reached significance were disease-free interval and anatomic resection (15), while Kumar analysed 71 patients who underwent surgery in India, and concluded that in their series, the only variables with an impact on survival were a history of extra-pulmonary metastasis and local lymph node invasion at the time of the primary tumour surgery (16). Taking broader view, we found research analysing metastases from kidney cancer (17), which observed a clear tendency towards a poorer survival rates with increasing lymph node stage, with mean survival times of 71.9, 50.7 and 36 months in patients with N0, N1 and N2 disease, respectively (17). Pfannschmidt et al. (18) also found similar results analysing survival after systematic lymphadenectomy in 245 patients with metastasis from colorectal cancer, kidney cancer or sarcoma (18).

In a meta-analysis published in 2013, Gonzalez et al. (10) analysed papers published between 2000 and 2011 assessing survival following the removal of pulmonary metastasis from colorectal cancer and based on more than 40 patients. They included 25 publications with data on a total of 2,925 patients. Pooled HRs were calculated using a random effects model for parameters considered potential prognostic factors. Four parameters were associated with poor survival:

(I) A short disease-free interval between primary tumour resection and development of lung metastases (HR 1.59; 95\% CI, 1.27-1.98);

(II) Multiple lung metastases (HR 2.04; $95 \%$ CI, 1.72-2.41);

(III) Positive hilar and/or mediastinal lymph nodes (HR 1.65 ; 95\% CI, 1.35-2.02);

(IV) Elevated prethoracotomy carcinoembryonic antigen (HR 1.91; 95\% CI, 1.57-2.32).

More recently, a recently reported meta-analysis of individual data from papers published between 2007 and 2014 (11) has analysed individual data from 3,501 patients from 17 studies. The objective of this meta-analysis was to assess the impact of previous liver metastasectomy on survival following lung metastasectomy. In individual data meta-analysis using multilevel random effects, it was observed that the variable with the greatest impact on survival was lymph node involvement, with an HR of 1.83 (95\% CI, 1.44-2.32). Adding to the variables with a negative impact on survival identified by Gonzalez (10), this study identified previous liver metastasis, positive surgical margins and size of the metastases (11).

Given all this, it is not surprising that reviews, such as that published by Chakedis and Schmidt in 2018 (19), list lymph node involvement among the risk factors for poor prognosis.

\section{Current attitude of thoracic surgeons towards systematic lymphadenectomy in patients with lung metastasis}

To assess the variability in the indications and types of surgery carried out in patients with lung metastasis, the Pulmonary Metastasectomy Working Group of the European Society of Thoracic Surgeons (ESTS) decided to carry out a survey among its members to gather data on 
current daily practice in surgery for lung metastasis (20). For this purpose, they developed a questionnaire of 39 questions and it was completed by 200 thoracic surgeons. In this questionnaire, there were three questions that address the topic of lymphadenopathy:

(I) Asked about indications or contraindications, $64 \%$ of respondents reported that the presence of mediastinal lymph node involvement was an absolute contraindication to metastasectomy and $32 \%$ considered it to be a relative contraindication. Only $4 \%$ of the participating surgeons considered that mediastinal lymph node metastasis was not a contraindication (20);

(II) Regarding lymph node status prior to surgery, only $3.7 \%$ of respondents claimed that they performed mediastinoscopy (1.4\%, always and $2 \%$, regularly), while $43.8 \%$ reported performing it rarely and $24 \%$ not at all (20);

(III) Concerning the surgical procedure itself, a third of the surgeons that responded (32\%) reported not doing any type of lymphadenectomy, while $55.5 \%$ of them took a sample and only $13 \%$ carried out complete mediastinal lymphadenectomy (20).

More recently, in 2013, Embun et al. published a prospective study with the largest number of patients undergoing surgery for lung metastasis from colorectal cancer reported to date. They included 543 patients, from 35 different hospitals, who underwent surgery between 2008 and 2010, providing a relatively up-to-date picture of the characteristics of operated cancer patients and the surgical technique used (21). Overall, only $9 \%$ of the patients underwent systematic lymphadenectomy (21) and 52\% of the interventions did not include any lymphadenectomy (21). To our knowledge, the most up-to-date and geographically broad analysis of current trends is found in the systematic review and meta-analysis of individual data published by Zabaleta et al. (11) in 2018. This study analysed data from 17 studies from nine different countries, and out of the 3,500 patients included in the study, there were no data on the status of the lymph nodes in 1,405 patients, implying that $41 \%$ of patients who underwent surgery did not undergo any type of lymphadenectomy (11).

\section{Risk factors for developing lymph node metastasis}

Given a lack of homogeneity in patient characteristics between studies and that lymphadenectomy is not performed systematically, to estimate the real percentage of patients with lymph node involvement and attempt to determine risk factors for lymph node dissemination, we have to rely on data from groups that do perform systematic lymphadenectomies. In 2014, Bölükbas et al. published the results of analysing surgery performed in 165 patients with pulmonary metastasis from colorectal cancer. In this review, they found a prevalence of lymph node metastases of $22.4 \%$ (22). The risk factors for developing lymph node metastasis were: number of pulmonary metastases, the primary cancer being rectal and extent of the resection procedure being greater than a wedge resection (that is, segmentectomy or lobectomy). A striking finding in this study was that there was a group of 17 patients with 4 or fewer pulmonary metastases who underwent atypical lung resection, none of whom had lymph node involvement (22).

A year later, Seebacher et al. published a study based on 313 metastasectomies from different types of cancer (23). In this case, the authors focused on unexpected metastases (unlike Bölükbas et al. who also included those detected in the preoperative assessment). Unexpected metastasis was found in $35.5 \%$ of patients with metastasis from breast cancer, $9.2 \%$ of those with metastasis from colorectal cancer and $20.8 \%$ of those with metastasis from kidney cancer (23). It is important to note that, in this series, only $10.5 \%$ of patients underwent preoperative positron-emission tomography and when findings of this imaging or computed tomography were positive, endobronchial ultrasound or mediastinoscopy were performed. The prognostic factors for developing lymph node involvement identified in this series were: a greater number of metastases and tumour diameter of more than $4 \mathrm{~cm}$ (23).

In 2018, Ali published a study on 160 patients who underwent surgery for lung metastasis from colorectal cancer, where lymphadenectomy was only performed if positron-emission or computed tomography findings suggested lymph node involvement or if the lymph nodes were found to be enlarged during surgery (24). Lymph nodes resected during surgery and those in which disease was detected during the postoperative follow-up were considered positive. Out of all 160 patients, 60 underwent lymphadenectomy, with positive findings in $8 \%$ of cases (5 patients) and among the other 100 patients, $23 \%$ (23 patients) developed lymph node involvement during follow-up. A larger number of pulmonary metastases and the primary cancer being in the colon were factors associated with a higher probability of developing mediastinal lymphadenopathies. A trend was observed in patients with 
Table 1 Risk factors for developing lymph node metastasis

\begin{tabular}{|c|c|c|c|c|c|}
\hline Author & Year & Country & Number of patients & $\begin{array}{c}\text { Systematic } \\
\text { lymphadenectomy (\%) }\end{array}$ & Risk factor \\
\hline Ali & 2018 & Republic of Korea & $160^{a}$ & 37.5 & Number of lung metastases \\
\hline Bölükbas & 2014 & Germany & $165^{\mathrm{a}}$ & 100 & Number of lung metastases \\
\hline \multirow[t]{2}{*}{ Seebacher } & 2015 & Germany & $209^{b}$ & 100 & Greater number of lung metastases \\
\hline & & & & & Tumour diameter $>4 \mathrm{~cm}$ \\
\hline
\end{tabular}

a, all patients with primary colorectal cancer; ${ }^{\mathrm{b}}$, patients with primary colorectal, breast or kidney cancer.

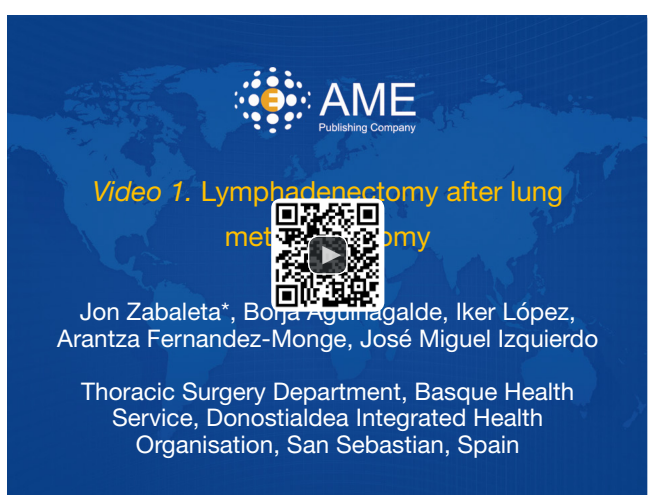

Figure 1 Lymphadenectomy after lung metastasectomy (33). Available online: http://www.asvide.com/article/view/32480

a history of liver metastasis and larger metastases, but the differences did not reach statistical significance (24). Table 1 summarises the findings of these three studies.

The origin of primary tumours may also affect the likelihood of lymph node involvement, as demonstrated by Welter et al. (25). They studied growth characteristics of different metastasis subtypes in the lung, and found that patients with metastases from melanoma showed an increased possibility of lymphangitic spread (27.8\%). Sarcoma metastases had the lowest incidence of lymphangitic spread (3.5\%), and patients with colorectal carcinoma or renal cell carcinoma mestastes intermediate risk for lymph node disease (18.0\% and $18.9 \%$ respectively) (25).

\section{Safety of systematic lymphadenectomy}

It should not be forgotten that when we say that systematic lymphadenectomy is a safe procedure, this does not mean that it is risk free (26). Few studies have analysed the impact of lymphadenectomy on postoperative complications due to lung metastases, but we could extrapolate from research assessing lymphadenectomies for the treatment of stage 1 lung cancer, given that these cases in principle would involve tumours of less than $4 \mathrm{~cm}$ in diameter and no lymph node involvement (27).

Watanabe et al. summarised the complications observed after lymphadenectomy by video-assisted thoracoscopy surgery in patients with early-stage lung cancer (26). In association with the lymphadenectomy, they observed chylothorax, recurrent paralysis, heart arrhythmia and pleural effusion (26). Analysing studies that only include stage I patients (28-32), authors reported complications related to the lymphadenectomy in between $6.3 \%$ and $13.8 \%$ of patients, the most common being heart arrhythmia (26).

Regarding research assessing survival in patients who underwent systematic lymphadenectomy, Renaud et al. also reported $5 \%$ of recurrent paralysis after surgery (14). Comparing series of patients who did and did not undergo lymphadenectomy in terms of complications, we can observe a slightly higher rate in those in whom this technique was performed: $14-23 \%(15,32)$ versus $4-8 \%$ patients in whom it was not performed $(9,16)$ (Figure 1). These data must be interpreted with caution, however, since lymphadenectomy is not the only cause of complications, and series with a higher rate of wedge resections are more likely to have a lower rate of complications (for a more comprehensive picture see the data summarised in Table 2).

\section{Does systematic Iymphadenectomy improve survival?}

This question is very difficult to answer. As we have 
Table 2 Complications observed

\begin{tabular}{|c|c|c|c|c|c|c|}
\hline Author & Year & $\begin{array}{l}\text { Number of } \\
\text { patients }\end{array}$ & $\begin{array}{c}\text { Systematic } \\
\text { lymphadenectomy (\%) }\end{array}$ & $\begin{array}{c}\text { Wedge } \\
\text { resection (\%) }\end{array}$ & $\begin{array}{l}\text { Positive lymph node } \\
\text { involvement (\%) }\end{array}$ & $\begin{array}{c}\text { Complications } \\
(\%)\end{array}$ \\
\hline Okumura & 2017 & 785 & 12 & 60 & 5 & 8 \\
\hline Kumar & 2018 & 71 & 0 & 85.9 & 2.8 & 4.2 \\
\hline Sponholz & 2018 & 224 & 100 & 30 & 23.6 & 23 \\
\hline
\end{tabular}

indicated, numerous factors have an impact on survival after pulmonary metastasectomy and it is difficult to compare different case series given that selection criteria may vary between research groups. Papers such as that published by Call et al. entitled, "Impact of inappropriate lymphadenectomy on lung metastasectomy for patients with metastatic colorectal cancer" may suggest the answer. This study analysed survival as a function of whether or not patients underwent lymphadenectomy (34). After analysing 522 patients of whom $48 \%$ underwent some type of lymphadenectomy (systematic, sampling, and minor lymphadenectomy in $20 \%, 34.8 \%$ and $45 \%$ of patients respectively), the authors observed that $44 \%$ of patients who did not undergo lymphadenectomy survived at least 5 years, while of 5 -year survival rate in those who did undergo lymphadenectomy was $58.3 \%$ or $24.8 \%$ respectively depending on whether or not there was lymph node involvement (34). They did not, however, analyse survival stratifying by whether or not systematic lymphadenectomy was performed, which is what would really provide an answer to the question posed above. If we compare the two study groups (34) using the data published on the Kaplan-Meier survival estimates at 60 and 70 months, patients who did not undergo lymphadenectomy had probabilities of survival of $39 \%$ and $15 \%$, respectively, compared to $41.60 \%$ and $13 \%$, for patients who underwent lymphadenectomy (34).

Hamaji et al. also analysed survival depending on whether or not systematic lymphadenectomy was performed in their study entitled "Is lymph node dissection required in pulmonary metastasectomy for colorectal adenocarcinoma?" (35). They analysed data from 518 patients, of whom 199 did not undergo any type of lymphadenectomy and 319 patients who did undergo lymphadenectomy. The 5-year survival rate was $47.1 \%$ in all patients, $48.3 \%$ in those who did not undergo lymphadenectomy, $49.3 \%$ in those who underwent lymphadenectomy and had no lymph node involvement, and $20 \%$ in those who underwent lymphadenectomy and did have lymph node involvement (35). In this paper, they conclude that the performance of lymphadenectomy can be recommended for prognostic purposes, although it does not improve survival. Table 3 lists some of the papers mentioned in this review, together with the reported survival rates and percentages of patients undergoing lymphadenectomy.

Before finishing this section, we would like to recall that there are no current consensus guidelines for deciding whether patients undergoing metastasectomy require adjuvant therapy (19), unlike in the case of those with primary lung cancer (36). In fact, in a paper published by Al-Almeri (8), in which patients were stratified by risk, low, medium and high (based on the criteria of Okumura), it was found that $17 \%, 18 \%$ and $29 \%$, respectively received chemotherapy, when it would be logical to expect that the low-risk group would receive less adjuvant treatment than the others. Additionally, it was found that, within each risk group, survival did not vary between those who were and were not given chemotherapy (8).

\section{Conclusions}

Thoracic lymph node involvement during surgery for lung metastasis is a negative prognostic factor. Despite the fact that systematic lymphadenectomy is a safe procedure, it is not complication free and increases surgical times. There is no scientific evidence that systematic lymphadenectomy improves the survival of patients with pulmonary metastases. We recommend performing this procedure systematically in centres seeking to investigate predictors of pulmonary metastases, given that not studying the lymph nodes might lead to their being insufficient data on a significant confounding factor. Nonetheless, we must always properly inform patients that the goal of lymphadenectomy is to estimate their prognosis as 
Table 3 Survival and percentage of patients with no lymph node assessment

\begin{tabular}{|c|c|c|c|c|c|c|}
\hline Okumura & 785 & 12 & 60 & 5 & 40 & 65.1 \\
\hline Kumar & 71 & 0 & 85.9 & 2.8 & 84 & 51.9 \\
\hline Sponholz & 224 & 100 & 30 & 23.6 & 0 & 46 \\
\hline Al-Ameri & 756 & NR & 81 & NR & NR & 56 \\
\hline Nanji & 420 & NR & 57 & 13 & 37 & 40 \\
\hline Renaud & 320 & 100 & 71 & 44 & 0 & 22.5 \\
\hline Pfannchmid & 245 & 100 & 59 & 15.7 & 0 & Median: 42.4 months \\
\hline
\end{tabular}

NR, not reported.

accurately as possible rather than to improve survival.

\section{Acknowledgments}

Funding: None.

\section{Footnote}

Provenance and Peer Review: This article was commissioned by the Guest Editor (Michel Gonzalez) for the series "Advancement in the Surgical Treatment of Pulmonary Metastasis" published in Fournal of Visualized Surgery. The article has undergone external peer review.

Conflicts of Interest: All authors have completed the ICMJE uniform disclosure form (available at http://dx.doi. org/10.21037/jovs.2019.05.08). The series "Advancement in the Surgical Treatment of Pulmonary Metastasis" was commissioned by the editorial office without any funding or sponsorship. The authors have no other conflicts of interest to declare.

Ethical Statement: The authors are accountable for all aspects of the work in ensuring that questions related to the accuracy or integrity of any part of the work are appropriately investigated and resolved.

Open Access Statement: This is an Open Access article distributed in accordance with the Creative Commons Attribution-NonCommercial-NoDerivs 4.0 International
License (CC BY-NC-ND 4.0), which permits the noncommercial replication and distribution of the article with the strict proviso that no changes or edits are made and the original work is properly cited (including links to both the formal publication through the relevant DOI and the license). See: https://creativecommons.org/licenses/by-nc-nd/4.0/.

\section{References}

1. Patrini D, Panagiotopoulos N, Lawrence D, et al. Surgical management of lung metastases. Br J Hosp Med 2017;78:192-8.

2. Pastorino $U$, Buyse $M$, Friedel $G$, et al. International Registry of Lung Metastases (1997) Long-term results of lung metastasectomy: prognostic analyses based on 5206 cases. J Thorac Cardiovasc Surg 113:37-49.

3. Krishnan K, Khanna C, Helman LJ. The Molecular Biology of Pulmonary Metastasis. Thorac surg Clin 2006;16:115-24.

4. Zabaleta J, Aguinagalde B, Fuentes MG, et al. Review and update of the prognostic factors in lung metastasis surgery. Cir Esp 2011;89:205-66.

5. Zabaleta J, Aguinagalde B, Fuentes MG, et al. Survival after lung metastasectomy for colorectal cancer: Importance of previous liver metastasis as a prognostic factor. EJSO 2011;9:786-90.

6. Belda-Sanchis J, Prenafeta-Claramunt N, MartínezSomolinos S, et al. Cirugía de las metástasis pulmonares. Arch Bronconeumol 2011;47:5-8.

7. Treasure T, Fallowfield L, Lees B. Pulmonary 
metastasectomy in colorectal cancer: the PulMiCC trial. Thorax 2012;67:185-7.

8. Al-Almeri M, Persson M, Bergman P, et al. Surgery for pulmonary metastases from colorectal cáncer: survival and prognostic factors. J Thorac Dis 2018;10:3372-80.

9. Okumura T, Boku N, Hishida T, et al. Surgical outcome and prognostic stratification for pulmonary metastasis from colorectal cancer. Ann Thorac Surg 2017;104:979-87.

10. Gonzalez M, Poncet A, Combescure C, et al. Risk factors for survival after lung metastasectomy in colorectal cancer patients: a systematic review and meta-analysis. Ann Surg Oncol 2013;20:572-9.

11. Zabaleta J, Iida T, Falcoz PE, et al. Individual data meta-analysis for the study of survival after pulmonary metastasectomy in colorectal cancer patients: A history of resected liver metastases worsens the prognosis. Eur J Surg Oncol 2018;44:1006-12.

12. García-Yuste M, Cassivi S, Paleru C. Thoracic lymphatic involvement in patients having pulmonary metastasectomy: incidence and the effect on prognosis. J Thorac Oncol 2010;5:S166-9.

13. Nanji S, Karim S, tang E, Brennan K, McGuire A, Pramesh CS, Booth CM. Pulmonary metastasectomy for colorectal cancer: predictors of survival in routine surgical practice. Ann Thorac Surg 2018;105:1605-12.

14. Renaud S, Alifano M, Falcoz PE, et al. Does nodal status influence survival? Results of a 19-year systematic lymphadenectomy experience during lung metastasectomy of colorectal cancer. Interact Cardiovasc Thorac Surg 2014;18:482-7.

15. Sponholz S, Schirren M, Oguzhan S, et al. Morbidity, mortality, and survival in elderly patients undergoing pulmonary metastasectomy for colorectal cancer. Int J Colorectal Dis 2018;33:1401-09.

16. Kumar NAN, Verma K, Shinde RS, et al. Pulmonary metastasectomy of colorectal cancer origin: Evaluating process and outcomes. J Surg Oncol 2018;118:1292-300.

17. Kudelin N, Bölükbas S, Eberlein M, et al. Metastasectomy With Standardized Lymph Node Dissection for Metastatic Renal Cell Carcinoma: An 11-Year Single-Center Experience. Ann Thorac Surg 2013;96:265-71.

18. Pfannschmidt J, Klode J, Muley T, et al. Nodal Involvement at the Time of Pulmonary Metastasectomy: Experiences in 245 Patients. Ann Thorac Surg 2006;81:448-54.

19. Chakedis J, Schmidt CR. Surgical treatment of metastatic colorectal cancer. Surg Oncol Clin N Am 2018;27:377-99.

20. Internullo E, Cassivi SD, Van Raemdonck D, et al. A Survey of Current Practice Amongst Members of the
European Society of Thoracic Surgeons. J Thorac Oncol 2008;3:1257-66.

21. Embun R, Fiorentino F, Treasure T, et al. Pulmonary metastasectomy in colorectal cancer: a prospective study of demography and clinical characteristics of 543 patients in the Spanish colorectal metastasectomy registry (GECMPCCR). BMJ Open 2013;3:e002787

22. Bölükbas S, Sponholz S, Kudelin N, et al. Risk factors for lymph node metastases and prognosticators of survival in patients undergoing pulmonary metastasectomy for colorectal cancer. Ann Thorac Surg 2014;97:1926-32.

23. Seebacher G, Decker S, Fischer JR, et al. Unexpected lymph node disease in resections for pulmonary metastases. Ann Thorac Surg 2015;99:231-6.

24. Ali K, Cho S, Jang HJ, et al. Predictive Factors of Thoracic Lymph Node Metastasis Accompanying Pulmonary Metastasis from Colorectal Cancer. Thorac Cardiovasc Surg 2018. [Epub ahead of print]

25. Welter S, Arfanis E, Christoph D, et al. Growth patterns of pulmonary metastases: should we adjust resection techniques to primary histology and size? Eur J Cardiothorac Surg 2017;52:39-46.

26. Watanabe A, Miyajima M, Mishina T, et al. Video-assisted thoracoscopic surgery node dissection for lung cancer treatment. Surg Today 2017;47:1419-28.

27. Goldstraw P, Chansky K, Crowley J, et al. The IASLC Lung Cancer Staging Project: proposals for revision of the TNM stage groupings in the forthcoming (Eighth) edition of the TNM classification for lung cancer. J Thorac Oncol 2016;11:39-51.

28. Gharagozloo F, Tempesta B, Margolis M, et al. Videoassisted thoracic surgery lobectomy for stage I lung cancer. Ann Thorac Surg 2003;76:1009-15.

29. Whitson BA, Andrade RS, Boettcher A, et al. Videoassisted thoracoscopic surgery is more favorable than thoracotomy for resection of clinical stage I non-small cell lung cancer. Ann Thorac Surg 2007;83:1965-70.

30. Scott WJ, Allen MS, Darling G, et al. Video-assisted thoracic surgery versus open lobectomy for lung cancer: a secondary analysis of data from the American College of Surgeons Oncology Group Z0030 randomized clinical trial. J Thorac Cardiovasc Surg 2010;139:976- 81; discussion 981-3.

31. Boffa DJ, Kosinski AS, Paul S, et al. Lymph node evaluation by open or video-assisted approaches in 11,500 anatomic lung cancer resections. Ann Thorac Surg 2012;94:347-53.

32. Palade E, Passlick B, Osei-Agyemang T, et al. Videoassisted vs. open mediastinal lymphadenectomy for stage 
I non-small-cell lung cancer: results of a prospective randomized trial. Eur J Cardiothorac Surg 2013;44:244-9.

33. Zabaleta J, Aguinagalde B, López I, et al.

Lymphadenectomy after lung metastasectomy. Asvide 2019;6:184. Available online: http://www.asvide.com/ article/view/32480

34. Call S, Rami-Porta R, Embun R, et al. Impact of inappropriate lymphadenectomy on lung metastasectomy for patients with metastatic colorectal cancer. Surg Today 2016;46:471-8.

doi: $10.21037 /$ jovs.2019.05.08

Cite this article as: Zabaleta J, Aguinagalde B, López I, Fernandez-Monge A, Izquierdo JM. The role of lymphadenectomy during lung metastasectomy. J Vis Surg 2019;5:58.
35. Hamaji M, Cassivi SD, Shen KR, et al. Is lymph node dissection required in pulmonary metastasectomy for colorectal adenocarcinoma? Ann Thorac Surg 2012;94:1796-800.

36. Douillard JY, Rosell R, De Lena M, et al. Adjuvant vinorelbine plus cisplatin versus observation in patients with completely resected stage IB-IIIA non-small-cell lung cancer (Adjuvant Navelbine International Trialist Association [ANITA]): a randomised controlled trial. Lancet Oncol 2006;7:719-27. 